\title{
The EPAGE Internet Guideline as a Decision Support Tool for Determining the Appropriateness of Colonoscopy
}

\author{
Olivier Terraz ${ }^{a}$ Vincent Wietlisbach ${ }^{a, \dagger}$ Jean-Gabriel Jeannot ${ }^{a}$ \\ Bernard Burnand $^{a}$ Florian Froehlich ${ }^{b, c}$ Jean-Jacques Gonvers ${ }^{b}$ \\ Jennifer K. Harris ${ }^{a}$ John-Paul Vader ${ }^{a}$ \\ ${ }^{\mathrm{a}}$ Institute for Social and Preventive Medicine, and ${ }^{\mathrm{b}}$ Medical Outpatient Clinic, University Medical Centre, \\ University of Lausanne, Lausanne, and ${ }^{c}$ Department of Gastroenterology, University of Basle, \\ Basle, Switzerland
}

\section{Key Words}

Appropriateness of care $\cdot$ Colonoscopy $\cdot$ Clinical practice - European Panel on the Appropriateness of Gastrointestinal Endoscopy · Guidelines · Internet

\begin{abstract}
Background: Few studies have examined how physicians perceive guidelines, much less their perceptions of an Internet presentation of such guidelines. This study assessed physicians' acceptance of an Internet-based guideline on the appropriateness of colonoscopy. Methods: Gastroenterologists participating in an international observational study consulted an Internet-based guideline for consecutive patients referred for colonoscopy. The guideline was produced by the European Panel on the Appropriateness of Gastrointestinal Endoscopy (EPAGE), using a validated method (RAND). Through the use of questionnaires, physicians were asked their opinions and perspectives of the guideline and website. $\boldsymbol{R} \boldsymbol{e}$ sults: There were 289 patients included in the study. The mean time for consulting the website was $1.8 \mathrm{~min}$, and it was considered easy to use by $86 \%$ of physicians. The recommendations were easily located for $82 \%$ of patients and physicians agreed with the appropriateness in $86 \%$ of cases. According to the EPAGE criteria, colonos-
\end{abstract}

copy was appropriate, uncertain, and inappropriate in 59,28 , and $13 \%$ of patients, respectively. Conclusions: The EPAGE guideline was considered acceptable and user-friendly and the use, usefulness and relevance of the website were considered acceptable. However, its actual use will depend on the removal of certain organizational and cultural obstacles.

Copyright (C) 2005 S. Karger AG, Basel

\section{Introduction}

The potential of clinical practice guidelines to improve the quality of care and of the Internet to implement them is well accepted [1]. Nevertheless, little attention has been paid to how practicing physicians perceive panel-based judgments of the appropriateness of medical procedures. Additionally, the opinion of physicians about Internetpresented panel-based guidelines is unknown.

Guidelines, defined as systematically developed statements to assist the patient and the practitioner in decisions about appropriate health care in specific clinical circumstances, are intended to increase the quality of patient care and the efficient use of health care resources [2]. Many guidelines have been developed in the past decades [3] and systematic reviews on the strategies and approach-

\section{KARGER}

Fax +4161306 1234 E-Mail karger@karger.ch www.karger.com
(C) 2005 S. Karger AG, Basel 0012-2823/05/0712-0072\$22.00/0

Accessible online at: www.karger.com/dig
John-Paul Vader, MD, MPH

Institut Universitaire de Médecine Sociale et Préventive

Rue du Bugnon 17

CH-1005, Lausanne (Switzerland)

Tel. +41 2131472 80, Fax +41 2131449 54, E-Mail John-Paul.Vader@hospvd.ch 
es for implementing them in clinical practice have been undertaken [4-7]. Although the conclusions of these reviews, concerning the effectiveness of different strategies, are not straightforward, effectiveness was found to be usually related to a combination of different activities in a well-designed implementation plan [3, 8-10].

Considering its potential to disseminate information, and given its rapid growth and the decreasing technical and costing obstacles, the World Wide Web (www) is a promising media to implement recommendations for diagnosis and therapy by means of guidelines [11]. Before assessing the effectiveness of the Internet to implement guidelines (as opposed to mere dissemination), it is necessary to assess the acceptability of the Internet guideline in real clinical settings. A recent study conducted among physicians in Switzerland [12] showed a high acceptance of the use of clinical practice guidelines via the Internet, and it was the aim of this study to extend this question on a European level. Thus, the objectives of this study were to assess the acceptability of the European Panel on the Appropriateness of Gastrointestinal Endoscopy website (EPAGE: www.epage.ch) [13] for determining the appropriateness of colonoscopy in real clinical settings internationally, as well as to assess the acceptability of the recommendations contained in the guideline among physician specialists.

\section{Methods}

\section{Guideline}

The guideline for the appropriateness of colonoscopy used in this study was developed by the EPAGE using the RAND method [14-16]. The RAND method is one of the most widely accepted methods of determining appropriateness of care [17]. It combines scientific evidence with systematically elicited and quantified expert opinion about the appropriateness of care. The members of the multidisciplinary international expert panel examined existing evidence summarized in a comprehensive literature review and rated the appropriateness of all possible indications for colonoscopy on a nine-point scale (1-3 inappropriate; 4-6 uncertain; 7-9 appropriate) [16]. A colonoscopy was considered appropriate if the expected health benefits outweighed the expected negative consequences by a sufficiently wide margin that the procedure was worth doing $[14,18]$.

This guideline was then transcribed into HTML (Hyper Text Mark-up Language) and made available on the Internet (www. epage.ch). After a simple registration, the website invites users to select, among 12 clinical situations, the indication for colonoscopy most suitable for the patient and then to choose among different optional characteristics (age, gender, risk factor for colorectal cancer, symptoms, previous investigations, time interval since last colonoscopy, and current therapy). This leads to the specific clinical indication for the patient and to the EPAGE panel's vote dis- tribution of the appropriateness corresponding to that indication for colonoscopy. Further elements of the site include access to abstracts or full-text articles related to the clinical situation concerned.

\section{Participating Physicians}

Physicians who participated in this study were gastroenterologists practicing in centers that took part in a large multicenter observational research project examining several aspects of the appropriate use of colonoscopy. A sample of 23 centers for digestive diseases in 10 European countries (Switzerland, France, Germany, Italy, Spain, Great Britain, Czech Republic, Poland, Denmark, Sweden) and Canada participated in this study, which was conducted between May 2001 and November 2001.

Gastroenterologists participating in this aspect of the study were asked to consult the EPAGE Internet guideline for 20 consecutive patients referred for colonoscopy and to respond to two questionnaires.

\section{Questionnaires}

For each patient, physicians were asked to complete questionnaire A which collected information on the duration of the consultation, the accessibility of the web guideline (or reasons for not consulting it), their own opinion about the appropriateness of the procedure, the relevance of the website in the care of the patient, and whether the appropriateness of the procedure was an issue for consideration.

Additionally, after the inclusion of all 20 patients, each participating endoscopist was asked to complete questionnaire B. Questionnaire B collected information on the overall acceptability of the website in terms of ease of access, use, usefulness of content, and learning experience. Other questions centered on obstacles to accessibility, use and usefulness of the guideline. A final section was related to the use of other guidelines and to computer equipment.

\section{Results}

\section{Consulting the EPAGE Website at the Time of the Patient Visit}

Of the 23 centers for digestive diseases practicing colonoscopy, 17 sent back between 6 and 25 questionnaires A, for a total of 289 patients. Patient age ranged from 16 to 90 years (mean $57 \pm 16 \mathrm{SD}$ ), and $54 \%$ of patients were female. The guideline was not consulted in 4 situations - mainly because of lack of time - and the website not accessible for 21 patients. The mean time required for consulting the EPAGE website was $1.8 \mathrm{~min}$, which was, on average, $1 / 8$ th of total consultation time.

From table 1, the number of positive responses to specific questions regarding the physicians' acceptability of the EPAGE guidelines and website can be seen. Using the EPAGE website was considered easy in $86 \%$ of the clinical situations encountered, and the proposed recommendations were easily located for $82 \%$ of the patients. Ad- 
Table 1. Physicians' acceptability of the EPAGE guideline via the Internet for the clinical situations encountered $(n=289)$
Questions about the EPAGE guideline

Number (\%)

of positive answers

Were you able to access the website?

$251(92)$

Were you able to use the website without difficulty?

$242(86)$

Did you locate the EPAGE guideline recommendation without difficulty? $220(82)$

Was the EPAGE guideline of assistance to you for the care of this patient? $76(27)$

Did you discuss the use of the EPAGE guideline with this patient?

$13(5)$

Was the appropriateness of colonoscopy a real concern for this patient?

Table 2. Appropriateness of colonoscopy for the main clinical situations according to the EPAGE criteria

\begin{tabular}{|c|c|c|c|c|}
\hline \multirow[t]{2}{*}{ Clinical situations according to the EPAGE criteria } & \multicolumn{4}{|c|}{ Appropriateness of colonoscopy, $\mathrm{n}(\%)$} \\
\hline & appropriate & uncertain & inappropriate & total \\
\hline Iron-deficiency anemia & $7(100)$ & 0 & 0 & 7 \\
\hline Rectal bleeding & $26(57)$ & $18(39)$ & $2(4)$ & 46 \\
\hline Uncomplicated lower abdominal pain $\geq 2$ months & $10(28)$ & $17(47)$ & $9(25)$ & 36 \\
\hline Change in bowel habits $\geq 2$ months & $24(80)$ & $2(7)$ & $4(13)$ & 30 \\
\hline Uncomplicated diarrhea & $14(50)$ & $12(43)$ & $2(7)$ & 28 \\
\hline Evaluation of known ulcerative colitis & $17(68)$ & $4(16)$ & $4(16)$ & 25 \\
\hline Evaluation of known Crohn's disease & $6(55)$ & $2(18)$ & $3(27)$ & 11 \\
\hline Screening for colorectal cancer in patients with known ulcerative colitis & 0 & 0 & 0 & 0 \\
\hline Screening for colorectal cancer in patients with known Crohn's disease & 0 & 0 & 0 & 0 \\
\hline Surveillance after polypectomy or curative surgery for colorectal cancer & $37(64)$ & $12(21)$ & $9(16)$ & 58 \\
\hline Screening for colorectal cancer in asymptomatic patients & $6(46)$ & $5(38)$ & $2(15)$ & 13 \\
\hline Miscellaneous indications & $17(77)$ & $4(18)$ & $1(5)$ & 22 \\
\hline Total & $164(59)$ & $76(28)$ & $36(13)$ & $276^{\mathrm{a}}$ \\
\hline
\end{tabular}

a 13 missing data.

ditionally, the appropriateness of colonoscopy was an issue of consideration for the gastroenterologists in $45 \%$ of patients, and the guideline was considered relevant to the care of specific patients in $27 \%$ of the clinical situations encountered. However, the use of the website was discussed with the patient in only $5 \%$ of the cases.

From table 2, the distribution of number of colonoscopies rated appropriate, uncertain and inappropriate, among the 12 main indication categories, can be seen. According to the EPAGE guideline, the proposed indications were appropriate, uncertain and inappropriate for 59,28 and $13 \%$ of patients, respectively. Table 3 shows the distribution of physicians' agreement and disagreement by the appropriateness category of the indication. Physicians agreed with the proposed appropriateness in $86 \%$ of the cases. Most cases of the disagreements (89\%)
Table 3. Physicians' agreement according to appropriateness of colonoscopy

\begin{tabular}{lrrlr}
\hline \multirow{2}{*}{$\begin{array}{l}\text { Physicians' } \\
\text { agreement }\end{array}$} & \multicolumn{4}{l}{ Appropriateness of colonoscopy, n (\%) } \\
\cline { 2 - 5 } & appropriate & uncertain & inappropriate & total \\
\hline Yes & $155(67)$ & $55(24)$ & $22(9)$ & 232 \\
No & $4(11)$ & $19(51)$ & $14(38)$ & 37 \\
\hline Total & $159(59)$ & $74(28)$ & $36(13)$ & $269^{\mathrm{a}}$
\end{tabular}

a 20 missing data. 
occurred when the proposed indication was either uncertain or inappropriate according to the EPAGE guideline.

\section{General Impressions on the Use of the EPAGE}

\section{Website}

When questionnaire $\mathrm{B}$, concerning the overall accessibility and usefulness of the Internet guideline, was examined, it was determined that of the 16 centres that sent back the questionnaire, 15 found accessing the EPAGE website to be easy or very easy and that the time required to access the website was acceptable. Reasons for not using the website were mainly lack of time, lack of access to computer in the consultation room and the presence of an obvious indication for colonoscopy. Twelve centers found the EPAGE guideline easy or very easy to use in order to assist in medical decisions, and 9 centers considered it useful as an aid to determine the appropriateness of medical procedures. Furthermore, 12 centers indicated they learned something from using the website.

The Internet was rated as having potential to vehicle clinical practice guidelines in general, in 14 centers. However, only 2 centers indicated the use of other guidelines from the web, yet 12 centers considered guidelines to be useful in deciding on patient care, whatever the support. In 2 centers, the use of the electronic guideline disturbed physicians' relation to their patients somewhat, while in 9 centers it disturbed the relation very little and in 4 centers not at all. Furthermore, 3 centers considered the use of the website as disturbing the patient and 3 as disturbing their pattern of work.

The number of centers planning to use the EPAGE site beyond the study period was 7 , and the main reasons cited for not continuing to use the website were the lack of computer access in the consulting room and the belief that the physician did not need it. Moreover, 2 centers made suggestions in regard to the improvement of the EPAGE site. One center recommended including additional options of patient characteristics, and the other center was concerned with the inability of the website to accommodate situations in which patients present more than one symptom.

As for the computer equipment and access, 14 centers had more than one computer in their practice. The computer that was used to access the EPAGE guideline was in the physician's office in 6 centers, in the examination room in 4 centers and in the secretariat in 3 centers ( 3 centers did not answer the question). The main computer applications generally used were word processing, email and web browser. Three quarters of the centers used more than three applications and all of them surfed on the Internet at least once a week, of which 15 did it to access medical sites. There was no apparent relationship between number of computer applications used - a reasonable proxy for computer literacy - and perceived ease of use of the guideline website.

\section{Discussion}

Access to the EPAGE guideline via the Internet was considered acceptable and user-friendly by participating European gastroenterologists. Agreement between the physician and the proposed appropriateness of the indication for colonoscopy was high. The Internet was generally considered to offer great potential to vehicle clinical practice guidelines, and the use, usefulness and relevance of the EPAGE Internet guideline were considered acceptable among this group of European gastroenterologists.

Recently, Jeannot et al. [12] reported a very high acceptance for the Internet to implement guidelines by Swiss physicians, and indicated obstacles to its actual use [12]. The present study, which was enlarged to the European level, focused on the form, content and functioning of the Internet guideline and its acceptance by physicians, showed similar results. The factors focused on for this study were all elements previously identified as important in the implementation of guidelines in general $[6,19]$.

The overall impression and use of the EPAGE Internet guideline by participating gastroenterologists was very promising. Access to the website was considered easy and the time required was acceptable. However, some centers stated that they would not continue to use the guideline beyond the study. The main reason cited for not continuing to use the guideline was the lack of computer in the consulting room, and since information is needed directly at the point of care [20], continuation was not feasible. Nonetheless, the culture surrounding informatics and the Internet are in constant flux and the number and use of computers in daily life are increasing, thus these obstacles should be re-examined in future studies.

Disturbance of the patient-physician relationship, a factor described as constraint in previous studies [21], was not considered as an obstacle in the use of this electronic guideline. However, mentioning the use of the EPAGE guideline to the patient was only done in a few cases. Knowing that public use of the Internet for health information is increasing and that patients are becoming more proactive in the management of care that concern them $[22,23]$, it was surprising to see how little the use 
of the electronic guideline was discussed with the patients. This may indicate a resistance to needed cultural change and/or may be an expression of some specialists not to give the impression they are not knowledgeable enough.

Out of the 289 patients that the gastroenterologists examined, the website guideline was not consulted in only 4 cases. The reason for not consulting the website was due to lack of time. However, these were highly motivated gastroenterologists; thus, the very low non-consulting rate seen in this study is most likely an underestimation of the use in general practice.

Ease of access, short access time and ease of use of the guideline are elements known to be necessary for a guideline to become a useful information resource, in addition to its relevant and valid content [20,22]. These elements were considered acceptable in the EPAGE guideline by the majority of the participating gastroenterologists. In one quarter of the patient situations encountered, the website was described as offering assistance in the care of the patients for whom it was consulted, and the general impression was even more favorable, with about half of the centers considering it as useful. The fact that the use of the guideline was described as useful in one quarter of the situations can be considered important, especially among this group of highly competent specialists. If the use of the guideline via the Internet can result in highly trained clinicians stopping to reflect on the appropriateness of this important procedure and can do so with a minimum of effort (less than 2 min per consultation), the potential for improving the quality of care for colonoscopy is considerable.

Although the validity of the guideline was not the object of this study, we can underline the high rate of surveyed physicians' agreement with the appropriateness proposed by EPAGE. Concordance between the practicing physicians and the expert panel about the rating of the appropriateness of a procedure has been the topic of previous research [24], which showed that there can be areas of disagreement. This raises the question of potential erroneous perception (in terms of under- or overestimation) specialist clinicians may have of the appropriateness of the procedure they perform [25-29]. It has been estimated that 2.4 million colonoscopies were performed in 1996 in the USA [30], and previous research has noted both overuse and underuse of colonoscopy depending on the clinical indication [18]. Thus, even if the guidelines were found to offer assistance to the participating gastroenterologists in only one quarter of patients, this would still result in a large improvement in the quality of care and a reduction of both overuse and underuse of colonoscopy.

The high competence of the participating specialists may explain why the usefulness of the guideline as a decision support tool was not rated higher. In most cases the physicians' judgment about appropriateness was identical to the EPAGE panel vote, as reflected in the high rate of agreement between the gastroenterologists and the proposed appropriateness. This rating of usefulness may be quite different among a population of general practitioners, who would probably benefit even more from guidelines than specialists. Also, the fact that participating physicians were specialists may explain some of their reluctance to use a tool assisting their decision, for fear of giving the impression they are not sufficiently knowledgeable. This may also find its reflection in the rather low rating of the learning experience of the use of the EPAGE guideline; the underpinning assumption being that they generally do what is appropriate. Nonetheless, it was necessary to firstly have the guideline and website tested by this highly specialized group of physicians to ensure the relevance, and acceptability of the guideline and the use, usefulness and user friendliness of the website. Since the guideline and website were accepted and used by the participating gastroenterologists, it is likely that they would also be accepted and used by other physicians; however, future research must be conducted to measure the acceptance, usefulness and use of the guideline and website by general practitioners.

\section{Conclusions}

This study found that the EPAGE guideline was considered acceptable and user-friendly by participating European gastroenterologists. Additionally, the use, usefulness and relevance of the website also were considered acceptable. However, the actual use of the EPAGE Internet guideline will depend on the removal of certain organizational and cultural obstacles. Although the Internet has the potential to offer an effective and wide-reaching tool for guideline implementation (as opposed to simple dissemination), the acceptability and relevance of the Internet for other guidelines needs to be evaluated for each specific guideline. 


\section{Acknowledgements}

This study benefited from financial support from the Swiss National Science Foundation, grant No 32-57244.99. We would like to thank all the physicians who participated in this study: J. Afonso-Debourse (FR), J.-C. Audigier (FR), C. Barthélemy (FR), C. Benoni (SE), J. Bures (CZ), P. Bytzer (DK), S. Chaussade (FR), K. Deinert (DE), R. D'Incà (IT), O. Dumas (FR), V. F. Eckardt (DE), F.-T. Fork (SE), R. Fried (CH), M. Gaudric (FR), S. Gianni (IT), R. Gnauck (DE), H.J. Gyrtrup (DK), J.M. Hansen (DK), R.J. Hils- den (CA), J. Hoch (CZ), R. Keil (CZ), M. Kohut (PL), M. Le Corguillé (FR), P. Matzen (DK), G. Meucci (IT), G. Minoli (IT), P. Moayyedi (GB), H. Neuhaus (DE), A. Nowak (PL), S. O'Mahony (GB), G. Payeras (ES), J.P. Piqueras (ES), J.-P. Rey (CH), J.-F. Rey (FR), S. Rejchrt (CZ), J. Ridpath (GB), T. Romanczyk (PL), M.A. Saez (ES), S. Sahm (DE), S. Sato (SE), B. Saunders (GB), P. Schmidt (DK), B. Schumacher (DE), J. Schwarz (CZ), M. Siroky (CZ), G.C. Sturniolo (IT), D. Swain (GB), E. Toth (SE), and M. Vance (GB).

\section{References}

1 Fraser HS, Kohane IS, Long WJ: Using the technology of the World Wide Web to manage clinical information. BMJ 1997;314:16001603.

2 Field MJ, Lohr KN: Clinical Practice Guidelines: Directions for a New Program. Institute of Medicine ed. Washington, National Academy Press, 1990.

\$3 Grol R, Grimshaw J: From best evidence to best practice: Effective implementation of change in patients' care. Lancet 2003;362: 1225-1230.

4 Grol R: Implementation of evidence and guidelines in clinical practice: A new field of research? Int J Qual Health Care 2000; 12:455456.

$\checkmark 5$ Grimshaw J, Russell I: Achieving health gain through clinical guidelines I: Developing scientifically valid guidelines. Qual Health Care 1993;2:243-248.

6 Grimshaw J, Russell I: Achieving health gain through clinical guidelines II: Ensuring guidelines change medical practice. Qual Health Care 1994;3:45-52.

7 Grimshaw J, Freemantle N, Wallace S, Russell I, Hurwitz B, Watt I, Long A, Sheldon T: Developing and implementing clinical practice guidelines. Qual Health Care 1995;4:55-64.

$\checkmark 8$ Grol R: Personal paper. Beliefs and evidence in changing clinical practice. BMJ 1997;315: 418-421.

$\checkmark 9$ Banait G, Sibbald B, Thompson D, Summerton C, Hann M, Talbot S: Modifying dyspepsia management in primary care: A cluster randomized controlled trial of educational outreach compared with passive guideline dissemination. Br J Gen Pract 2003;53:94-100.

-10 Silagy CA, Weller DP, Lapsley H, Middleton P, Shelby-James T, Fazekas B: The effectiveness of local adaptation of nationally produced clinical practice guidelines. Fam Pract 2002; 19:223-230.
11 Lowe HJ, Lomax EC, Polonkey SE: The World Wide Web: a review of an emerging internetbased technology for the distribution of biomedical information. J Am Med Inform Assoc 1996;3:1-14.

12 Jeannot JG, Scherer F, Pittet V, Burnand B Vader JP: Use of the World Wide Web to implement clinical practice guidelines: a feasibility study (Abstract). J Med Internet Res 2003; 5:e12.

13 Institute of Social and Preventive Medicine: EPAGE. [Available from: URL: http://www. epage.ch/ (Accessed on 20-10-2003)] Lausanne: 2002

14 Brook RH, Chassin MR, Fink A, Solomon DH, Kosecoff J, Park RE: A method for the detailed assessment of the appropriateness of medical technologies. Int J Technol Assess Health Care 1986;2:53-63.

15 Fitch K, Bernstein SJ, Aguilar MD, Burnand B, LaCalle JR, Lazaro P, van het Loo M, McDonnell J, Vader JP, Kahan JP: The RAND/ UCLA Appropriateness Method User's Manual. Santa Monica, RAND Corporation, 2001.

16 Vader JP, Burnand B, Froehlich F, Dubois RW, Bochud M, Gonvers JJ: The European Panel on Appropriateness of Gastrointestinal Endoscopy (EPAGE): project and methods. Endoscopy 1999;31:572-578.

17 Naylor CD: What is appropriate care? N Engl J Med 1998;338:1918-1920.

18 Vader JP, Pache I, Froehlich F, Burnand B, Schneider C, Dubois RW, Brook RH, Gonvers $\mathrm{JJ}$ : Overuse and underuse of colonoscopy in a European primary care setting. Gastrointest Endosc 2000;52:593-599.

19 Thomson R, Lavender M, Madhok R: How to ensure that guidelines are effective. BMJ 1995; 311:237-242.

20 Smith R: What clinical information do doctors need? BMJ 1996;313:1062-1068.

-21 Bodenheimer T, Grumbach K: Electronic technology: a spark to revitalize primary care? JAMA 2003;290:259-264.

-22 Jadad AR: Promoting partnerships: Challenges for the internet age. BMJ 1999;319:761764.
23 Murray E, Lo B, Pollack L, Donelan K, Catania J, White M, Zapert K, Turner R: The impact of health information on the internet on the physician-patient relationship: patient perceptions. Arch Intern Med 2003;163:1727-1734.

24 Ayanian JZ, Landrum MB, Normand SL, Guadagnoli E, McNeil BJ: Rating the appropriateness of coronary angiography - do practicing physicians agree with an expert panel and with each other? N Engl J Med 1998;338:18961904

25 de Bosset V, Froehlich F, Rey JP, Thorens J, Schneider C, Wietlisbach V, Vader JP, Burnand B, Muhlhaupt B, Fried M, Gonvers JJ: Do explicit appropriateness criteria enhance the diagnostic yield of colonoscopy? Endoscopy $2002 ; 34: 360-368$.

-26 Froehlich F, Pache I, Burnand B, Vader JP, Fried M, Beglinger C, Stalder G, Gyr K, Thorens J, Schneider C, Kosecoff J, Kolodny M, Dubois RW, Gonvers JJ, Brook RH: Performance of panel-based criteria to evaluate the appropriateness of colonoscopy: a prospective study. Gastrointest Endosc 1998;48:128-136.

27 Grilli R, Magrini N, Penna A, Mura G, Liberati A: Practice guidelines developed by specialty societies: the need for a critical appraisal. Lancet 2000;355:103-106.

-28 Minoli G, Meucci G, Bortoli A, Garripoli A, Gullotta R, Leo P, Pera A, Prada A, Rocca F, Zambelli A: The ASGE guidelines for the appropriate use of colonoscopy in an open access system. Gastrointest Endosc 2000;52:39-44.

29 Vader JP, Wietlisbach V, Burnand B, Froehlich F, Gonvers JJ, the EPAGE Study Group: Gastroenterologists overestimate the appropriateness of colonoscopies they perform (abstract). Gastroenterology 2003;124:A-354.

30 Owings MF, Kozak LJ: Ambulatory and inpatient procedures in the United States, 1996. Vital Health Stat 1998;13;1-119. 